\title{
Capsaicin induces apoptosis and autophagy in human melanoma cells
}

\author{
HAIHAN CHU* ${ }^{*}$ MENG LI* and XIUCHUN WANG \\ Department of Burn and Plastic Surgery, Jining First People's Hospital, Jining, Shandong 272011, P.R. China
}

Received August 5, 2018; Accepted February 8, 2019

DOI: $10.3892 /$ ol.2019.10206

\begin{abstract}
Melanoma is the most lethal type of skin cancer; rapid metastasis and resistance to conventional radio- and chemotherapy make melanoma the most aggressive type of skin cancer. In addition, there is a high recurrence rate within 1 year among patients with melanoma following traditional treatment by chemotherapy or immunotherapy, and these treatment options are only useful in advanced stages. As the efficiency of treatment options for melanoma is not ideal, the present study aimed to confirm that capsaicin has inhibitory effects on the human melanoma A375 and C8161 cell lines in vitro. Capsaicin, the active component of peppers, has been reported to possess substantial anticarcinogenic and antimutagenic activities. Additionally, capsaicin exhibits an inhibitory effect on tumor growth in numerous malignant cell lines. In the present study, flow cytometry, fluorescent puncta detection and western blotting were performed. The experimental results indicated that capsaicin activated apoptosis, and that apoptosis induction was associated with poly(ADP-ribose) polymerase (PARP) cleavage and activation of caspase-3. Additionally, the formation of autophagosomes and accumulation of microtubule-associated proteins $1 \mathrm{~A} / 1 \mathrm{~B}$ light chain 3B-II and beclin 1 suggested that capsaicin induced autophagy in human melanoma cells. Furthermore, inhibiting capsaicin-induced autophagy promoted the activation of cleaved caspase-3 and PARP proteins, which are associated with apoptosis. In addition, inhibition of autophagy using 3-MA enhanced capsaicin-induced cell death, indicating that capsaicin-induced autophagy is a pro-survival process in cells. In conclusion, the results of the present study revealed that capsaicin induced cell apoptosis and autophagy in human melanoma cells and capsaicin may be considered as a novel candidate drug for melanoma treatment.
\end{abstract}

Correspondence to: Miss Xiuchun Wang, Department of Burn and Plastic Surgery, Jining First People's Hospital, 6 Jiankang Road, Jining, Shandong 272011, P.R. China

E-mail: wangxiuchunwxc@163.com

${ }^{*}$ Contributed equally

Key words: apoptosis, autophagy, chemotherapy, melanoma

\section{Introduction}

Melanoma is a malignancy of melanocytes, which originate from pigment-producing cells initially derived from the neuroectoderm that can be found throughout the skin, iris and rectum (1). An epidemiological study has demonstrated that ultraviolet radiation exposure and severe sunburns are the major risk factors for developing melanoma (2). The cutaneous form of the disease is common in the Western world; 76,380 new cases and 10,130 cases of cancer-associated mortality were attributed to melanoma in the United States in 2016 (3), and it caused the majority (75\%) of cases of skin cancer-associated mortality. It has been reported that the global incidence rate of melanoma is $15-25 / 100,000$ individuals (4), with an increase in melanoma-associated mortality every year. Following traditional therapy, the 5-year survival rate of patients with metastatic melanoma is consistently $<10 \%$ in the majority of cases (5). Additionally, until 2010 no randomized clinical trial could provide evidence that the survival rate can be improved for those with advanced-stage metastatic melanoma (1). Therefore, investigating effective agents or adjuvant therapies for the treatment of melanoma is a continuing concern.

Capsaicin (8-methyl-N-vanillyl-6-nonenamide) is one of the ingredients in capsicum, the active component of peppers. While chili peppers are extensively used in food as a pungent spice (6), China is one of the first countries to use peppers as a medicine. Capsaicin is a major active compound from chili peppers and has numerous beneficial roles in humans, which are similar with the practice of Traditional Chinese Medicine. In Traditional Chinese Medicine, peppers are used to treat various diseases, including abdominal pain, colds and rheumatism. Previous studies have documented that capsaicin has anti-inflammatory, analgesic, anesthetic and detoxification effects (7-10). Furthermore, a previous study has reported that capsaicin is a potential agonist of transient receptor potential cation channel subfamily $\mathrm{V}$ member 1 , and may exert its effects through the receptor-dependent pathway and the receptor-independent pathway (6). In addition, by inducing apoptosis and autophagy in numerous types of malignant cell lines, studies have revealed that capsaicin has an inhibitory effect on tumor growth, which demonstrates that capsaicin has potential anticancer effects (11), including in prostate cancer cells (12), human nasopharyngeal carcinoma (13), colon adenocarcinoma $(14,15)$ and hepatocellular carcinoma (16). However, to the best of our knowledge, no study 
has investigated whether capsaicin could induce apoptosis and autophagy in human melanoma cells.

Apoptosis and autophagy are two types of programmed cell death (PCD). Cell death can be classified through morphological differences as a hallmark of cancer. Apoptosis is characterized by cell shrinkage, dynamic membrane blebbing, nuclear condensation and fragmentation, and loss of adhesion to neighboring cells or the extracellular matrix (17). Inducing cell apoptosis is considered a reasonable and promising chemopreventive or chemotherapeutic strategy for tumor cells (18). Autophagy, or type II PCD, is a cellular self-catabolic process: Cytoplasmic constituents are isolated in double membrane vesicles, through the lysosome-dependent machinery, and fused by lysosomes where they are degraded (19). Autophagy is a tightly regulated strategy developed by cells to provide energy and nutrients by digesting long-lived or damaged cytosolic proteins and organelles. As a novel cancer therapy, targeting PCD through modulation of autophagy could be an effective approach for alleviating treatment resistance in apoptosis-defective tumor cells (20). Under certain circumstances, autophagy constitutes a stress adaptation that suppresses apoptosis (21). This is a complex functional association between apoptosis and autophagy, which serves critical functions in cancer development and progression.

The aim of the present study was to determine whether it is possible for capsaicin to suppress human melanoma cells in vitro, and to investigate the effect of capsaicin on induction of apoptosis and autophagy in human melanoma cells. Furthermore, the functional association between apoptosis and autophagy was investigated.

\section{Materials and methods}

Chemicals and reagents. Capsaicin (purity $>98 \%$ ) was purchased from Shanghai Yuanye Bio-technology Co., Ltd. (Shanghai, China). Dulbecco's modified Eagle's medium (DMEM), trypsin, fetal bovine serum (FBS) and dimethyl sulfoxide (DMSO) were purchased from Gibco; Thermo Fisher Scientific, Inc. (Waltham, MA, USA). EDTA-free trypsin was purchased from HyClone; GE Healthcare Life Sciences (Logan, UT, USA). A fluorescein isothiocyanate (FITC)-Annexin V kit was obtained from Nanjing KeyGen Biotech Co., Ltd. (Nanjing, China). Propidium iodide (PI) was purchased from Takara Bio, Inc. (Otsu, Japan). 3-methyladenine (3-MA) was purchased from Selleck Chemicals (Houston, TX, USA). Antibodies against cleaved poly (ADP-ribose) polymerase (cleaved-PARP) (cat no. 5625), cleaved caspase-3 (cat no. 9664), microtubule-associated proteins 1A/1B light chain 3B (LC3B) (cat no. 3868), beclin 1 (cat no. 3495) and GAPDH (cat no. 5174) were purchased from Cell Signaling Technology, Inc. (Danvers, MA, USA).

Cell lines and cell culture. The human melanoma A375 and C8161 cell lines were obtained from Peking Union Cell Resource Center (Beijing, China). The cells were cultured in DMEM supplemented with $1 \%$ penicillin-streptomycin and $10 \% \mathrm{FBS}$ in a humidified atmosphere with $5 \% \mathrm{CO}_{2}$ at $37^{\circ} \mathrm{C}$. A 375 and C8161 cells in the treatment group were treated with different concentrations of capsaicin $(0,25,50,100,200$ and $400 \mathrm{Mm}$ ) at $37^{\circ} \mathrm{C}$ for 24 or $48 \mathrm{~h}$, whereas cells in the control group were treated with equivalent volumes of DMSO.
Cell viability assay. The effect of capsaicin on cell viability was measured using a Cell Counting kit-8 (CCK8; Dojindo Molecular Technologies, Inc., Kumamoto, Japan) assay. A375 and C8161 cells (100 $\mu 1)$ were seeded in a 96-well plate at a density of $2 \times 10^{4}$ cells $/ \mathrm{ml}$ and were incubated overnight at $37^{\circ} \mathrm{C}$ in an atmosphere containing $95 \%$ air and $5 \% \mathrm{CO}_{2}$. Subsequently, the cells were treated with various concentrations of capsaicin $(25,50,100,200$ and $400 \mu \mathrm{M}$ ). After 24 or $48 \mathrm{~h}, 10 \mu \mathrm{l} \mathrm{CCK} 8$ solution was added to each well for $2 \mathrm{~h}$ at $37^{\circ} \mathrm{C}$ according to the manufacturer's protocol. The absorbance at $450 \mathrm{~nm}$ was measured using the iMark microplate reader (Molecular Devices, LLC, Sunnyvale, CA, USA).

Apoptosis analysis by flow cytometry. A375 cells $\left(5 \times 10^{4}\right.$ cells $\left./ \mathrm{ml}\right)$ were placed in 6 -well culture plates and treated with capsaicin at indicated concentrations $(0,50,100$, and $200 \mu \mathrm{M}$ ) or DMSO for $24 \mathrm{~h}$. Following capsaicin treatment, the cells were harvested by EDTA-free trypsin, washed twice with cold PBS and resuspended in binding buffer at a concentration of $1 \times 10^{6}$ cells $/ \mathrm{ml}$. Subsequently, cells were incubated with FITC-conjugated Annexin V and PI (5 $\mu \mathrm{l}$ each) for $15 \mathrm{~min}$ at room temperature in the dark. Subsequently, the samples were analyzed using a flow cytometer r3.1 (FACSCalibur; BD Biosciences, San Jose, CA, USA).

LysoTracker ${ }^{\circledR}$ red staining. A375 cells were seeded in 6-well plates ( $1 \mathrm{ml}$ per well) at a density of $5 \times 10^{5}$ cells $/ \mathrm{ml}$ and treated with or without $100 \mu \mathrm{M}$ capsaicin for $24 \mathrm{~h}$ at $37^{\circ} \mathrm{C}$. Subsequently, the cells were incubated with $50 \mathrm{nM}$ LysoTracker ${ }^{\circledR}$ Red DND-99 (Invitrogen; Thermo Fisher Scientific, Inc.) in the dark for $30 \mathrm{~min}$ at $37^{\circ} \mathrm{C}$. Immunofluorescence images were captured using a confocal laser scanning microscope (Leica Microsystems GmbH, Wetzlar, Germany).

Green fluorescent protein (GFP)-LC3 puncta assay. The formation of fluorescent puncta of autophagosomes was analyzed in cells transfected with GFP-LC3. A375 cells were cultured in 6-well plates at a density of $5 \times 10^{5}$ cells $/ \mathrm{ml}$ and transfected with $2 \mu \mathrm{g} / \mathrm{ml}$ GFP-LC3 plasmid (Genomeditech (Shanghai) Co., Ltd., Shanghai, China), using Lipofectamine ${ }^{\circledR}$ 2000 (Invitrogen; Thermo Fisher Scientific, Inc.), according to the manufacturer's protocol. After $24 \mathrm{~h}$ post-transfection, the cells were treated with or without $100 \mu \mathrm{M}$ capsaicin for $24 \mathrm{~h}$ at $37^{\circ} \mathrm{C}$. Immunofluorescence images were captured using a fluorescence microscope.

Western blot analysis. A375 cells were cultured in 6-well plates at a density of $5 \times 10^{5}$ cells $/ \mathrm{ml}$ and treated with capsaicin $(0,50,100$ and $200 \mu \mathrm{M})$ for $24 \mathrm{~h}$ at $37^{\circ} \mathrm{C}$. Cells were lysed in ice-cold radioimmunoprecipitation assay buffer (Beyotime Biotechnology Co. Ltd., Shanghai, China) containing a protease and phosphatase inhibitor cocktail for $30 \mathrm{~min}$ on ice, centrifuged at $13,000 \mathrm{x}$ g for $15 \mathrm{~min}$ at $4^{\circ} \mathrm{C}$ and the supernatant was collected. A Pierce bicinchoninic acid protein assay kit (Pierce; Thermo Fisher Scientific, Inc.) was used to quantify the protein concentration. Subsequently, 10\% SDS-PAGE was performed. Equivalent amounts of protein $(40 \mu \mathrm{g})$ were loaded, separated and transferred to a polyvinylidene difluoride membrane (EMD Millipore, Billerica, MA, USA). After 

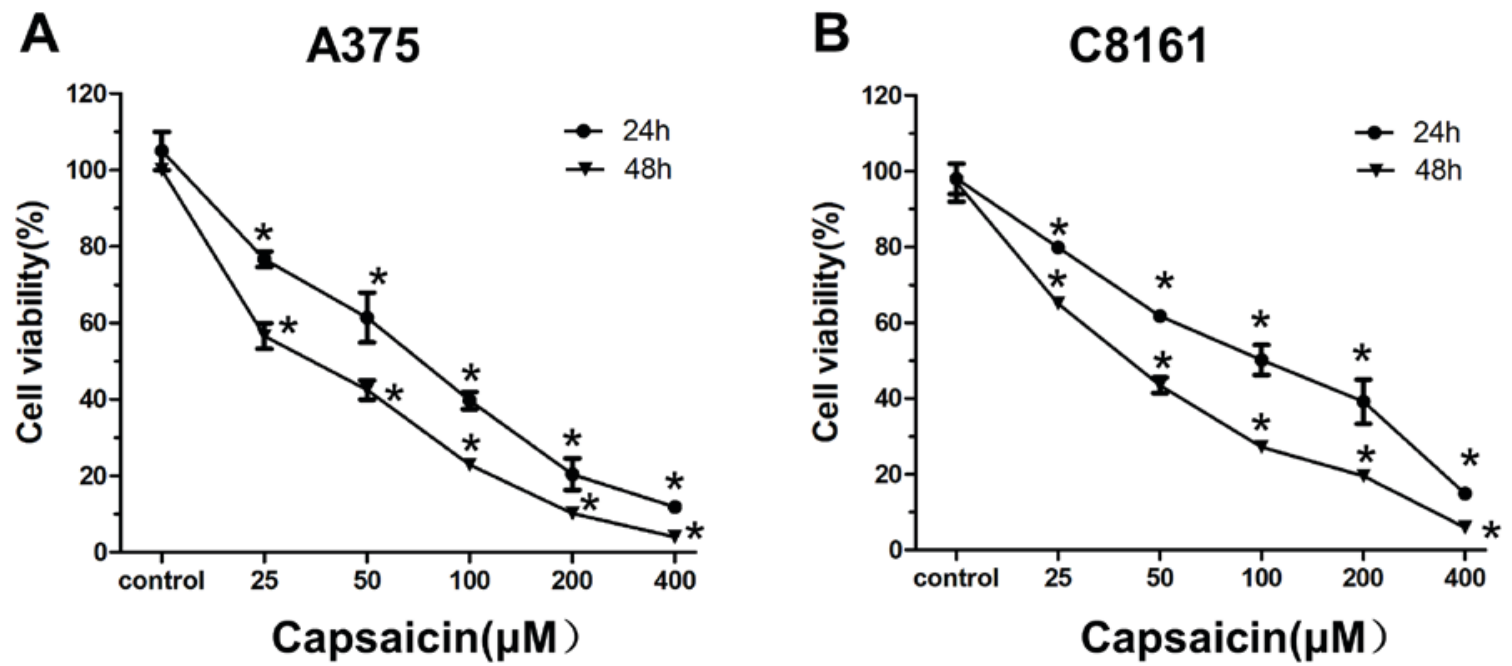

Figure 1. Inhibitory effect of capsaicin on cell viability in human melanoma A375 and C8161 cell lines. Cells were treated with various concentrations of capsaicin $(25,50,100,200$ and $400 \mu \mathrm{M})$ for 24 or $48 \mathrm{~h}$. A Cell Counting kit-8 assay was performed to assess melanoma cell viability. (A) Growth of A375 cells was inhibited in a dose- and time-dependent manner following capsaicin treatment. (B) Dose- and time-dependent response of C8161 cells following capsaicin exposure for 24 or $48 \mathrm{~h}$. "P<0.05 compared with control group.

blocking in $5 \%$ non-fat milk for $1 \mathrm{~h}$ at room temperature, the membranes were incubated with primary antibodies $(1: 1,000$; cleaved-PARP, cleaved caspase-3, LC3B, beclin 1 and GAPDH) at $4^{\circ} \mathrm{C}$ overnight. Subsequently, the membranes were washed and incubated with horseradish peroxidase-conjugated secondary antibody (cat. no. 7074s; Cell Signaling Technology, Inc.; dilution, 1:5,000) for $1 \mathrm{~h}$ at room temperature. Proteins were detected using an enhanced chemiluminescence kit (EMD Millipore).

Statistical analysis. All data represent at least three independent experiments and are expressed as the means \pm standard deviation. Student's t-test was used to compare differences between two groups, and one-way ANOVA analysis of variance and Dunnett's post hoc test were used for calculating the significance between different groups. All statistical analyses were performed using SPSS v19.0 software (IBM Corp., Armonk, NY, USA). ${ }^{*} \mathrm{P}<0.05$ was considered to indicate a statistically significant difference.

\section{Results}

Capsaicin inhibits A375 and C8161 cell viability. The impact of the inhibitory effects of capsaicin in human melanoma cells was investigated. A375 and C8161 cells were treated with various concentrations of capsaicin $(25,50,100,200$ and $400 \mu \mathrm{M}$ ) for 24 or $48 \mathrm{~h}$. Subsequently, cell viability was measured by the CCK8 assay. As shown in Fig. 1, the viability of melanoma cells was significantly decreased following capsaicin treatment, which indicated that capsaicin caused cell viability inhibition in a time- and dose-dependent manner.

Capsaicin induces apoptosis of human melanoma cells. Flow cytometry was performed to ascertain whether capsaicin induced apoptosis, which may mediate the inhibitory effects of capsaicin on human melanoma cell viability. The results demonstrated that treatment of melanoma cells with capsaicin resulted in a dose-dependent increase in apoptotic cells (Fig. 2A and B). Furthermore, specific signaling proteins involved in apoptosis were investigated by western blotting. As shown in Fig. 2C, the expression levels of cleaved caspase-3 and cleaved PARP were increased in the A375 and C8161 cells following capsaicin treatment. These data indicated that capsaicin promoted caspase-dependent apoptosis to decrease A375 and C8161 cell viability.

Capsaicin activates autophagy in human melanoma cells. To determine whether capsaicin may trigger autophagy in melanoma cells, the LysoTracker ${ }^{\circledR}$ Red and GFP-LC3 puncta transfection methods were used to label cellular acidic compartments and analyze the formation of fluorescent puncta of autophagosomes, respectively. The results revealed that upon exposure to capsaicin $(100 \mu \mathrm{M})$ for $24 \mathrm{~h}$, the fluorescence intensity in melanoma cells exhibited a clear increase (Fig. 3A). Additionally, capsaicin treatment resulted in an increase in GFP-LC3 puncta formation in melanoma cells (Fig. 3B). To verify the aforementioned findings, autophagy-associated protein levels in the cytoplasm were assessed by western blotting. As shown in Fig. 3C, the expression levels of LC3B and beclin 1 in melanoma cells were increased in a concentration-dependent manner following capsaicin treatment, which indicated that capsaicin may induce autophagy in melanoma cells via the upregulation of autophagy-associated protein expression levels.

Capsaicin-induced autophagy inhibits apoptosis to protect cell survival. It has been reported that autophagy has a dual role in cancer, serving as an antagonist to block apoptotic cell death or to protect cell survival (20). Therefore, an autophagy inhibitor, 3-MA (2.5 mM), was used to investigate the role of autophagy in melanoma cells. The results revealed that 

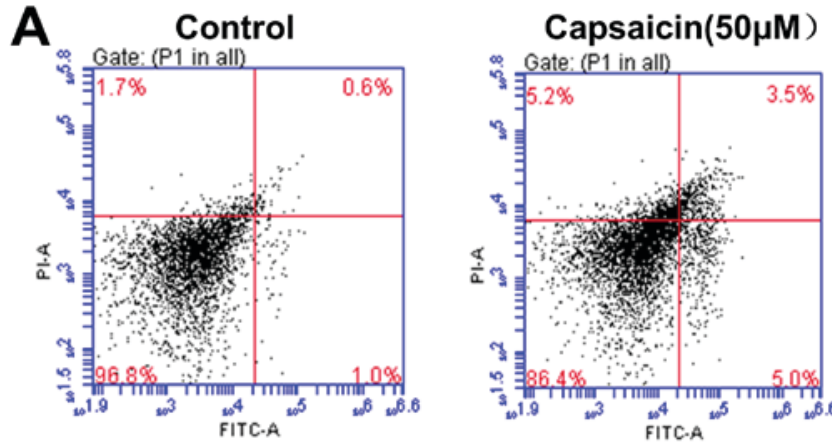

B

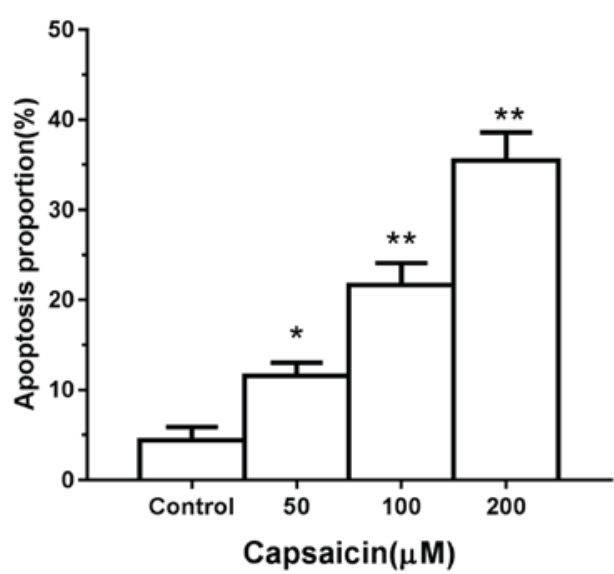

Capsaicin $(100 \mu \mathrm{M})$

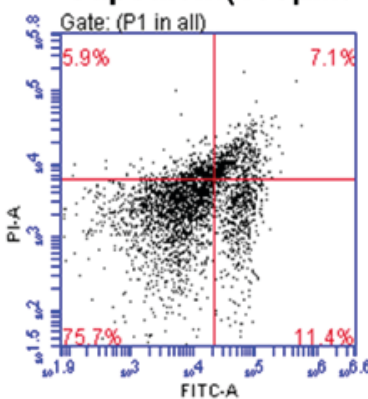

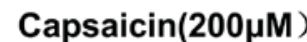

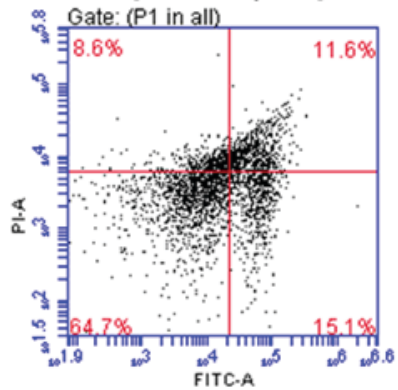

C

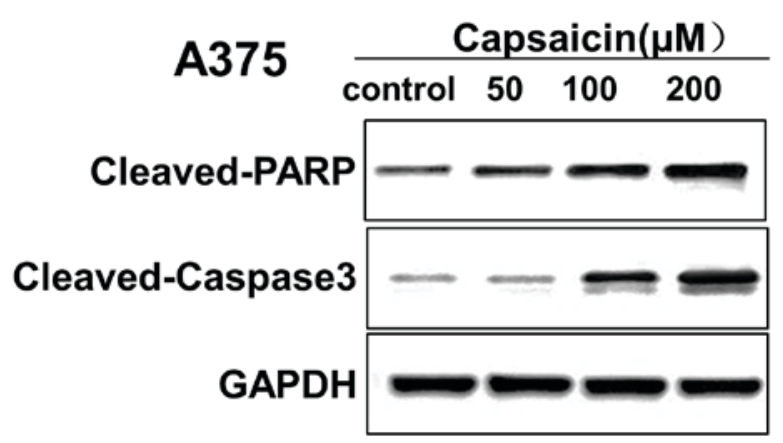

Figure 2. Capsaicin induces apoptosis of human melanoma cells. (A) Following treatment with three concentrations of capsaicin for 24 h, the cells were incubated with FITC-conjugated Annexin V/PI and apoptosis induction was analyzed by flow cytometry. (B) Quantification of the apoptosis rates of melanoma cells following capsaicin treatment. The histograms indicate the proportion of apoptotic cells from three separate experiments. (C) Cells were treated with various concentrations of capsaicin $(50,100$ and $200 \mu \mathrm{M})$ for $24 \mathrm{~h}$. Western blotting was used to analyze the expression levels of the apoptosis-associated proteins cleaved PARP and caspase- 3 . ${ }^{*} \mathrm{P}<0.05,{ }^{* *} \mathrm{P}<0.01$ compared with the control group.

following treatment with 3-MA, the inhibitory effect of capsaicin on cell viability were increased (Fig. 4A). Additionally, in response to autophagy inhibition, the A375 cells turned to apoptosis following capsaicin treatment, as demonstrated by the flow cytometry assay (Fig. 4B and C). Western blotting data revealed that the expression levels of cleaved caspase- 3 and cleaved PARP were increased following capsaicin and 3-MA treatment (Fig. 4D). In conclusion, capsaicin-induced apoptosis was increased by the inhibition of autophagy, which indicated that the autophagy induced by capsaicin may suppress apoptosis to protect cell survival.

\section{Discussion}

Melanoma is the most aggressive and treatment-resistant type of skin cancer (22) that arises from malignant transformation of melanocytes. The development of melanocytes is modulated by the receptor tyrosine kinase c-KIT and microphthalmia-associated transcription factor (23). Additionally, a 2002 genome-wide screen revealed that B-Raf proto-oncogene, serine/threonine kinase (BRAF) point mutations are highly frequent in melanoma and less frequent in other types of cancer (24). The adenosine triphosphate-competitive BRAF inhibitors, vemurafenib and dabrafenib, are targeted therapy options with substantial efficacy against melanoma, and provide similar clinical benefits $(25,26)$. However, vemurafenib and dabrafenib only produce rapid initial disease stabilization in melanoma (27). The emergence of drug resistance and disease progression, along with regressions on BRAF inhibitors, leads to the majority of patients to relapse within 1 year (28). Traditional treatment by chemotherapy or immunotherapy is only useful in the advanced stages. Over the last decade, several novel therapies for treating melanoma have emerged. A number of drugs can target specifically mutated melanoma cells, block or trigger important signaling pathways, or unblock immune checkpoints (29). Although there has been considerable progress in the melanoma-targeted therapy and immunotherapy field, there remains a great challenge to prevent the emergence of resistance (22). Capsaicin is a naturally occurring alkaloid and its biological effects have been extensively studied (30). Previous studies have demonstrated that capsaicin has a variety of pharmacological activities, including anti-itching (31), anti-inflammatory (9) and analgesic (32) effects. Additionally, capsaicin has attracted widespread interest due to its antitumor effects $(11,33,34)$ and it has been reported to exert notable effects on human melanoma cells. A previous study demonstrated that capsaicin could inhibit B16-F10 melanoma cell migration via the phosphatidylinositol 3-kinase/protein kinase B/Racl signaling pathway (35). Additional effects of capsaicin have been reported, including the reduction of proliferation and viability of cancer cells, by causing $\mathrm{G}_{2} / \mathrm{M}$ phase arrest and resulting in activation of caspase-3, -8 and -9 , which are associated with 

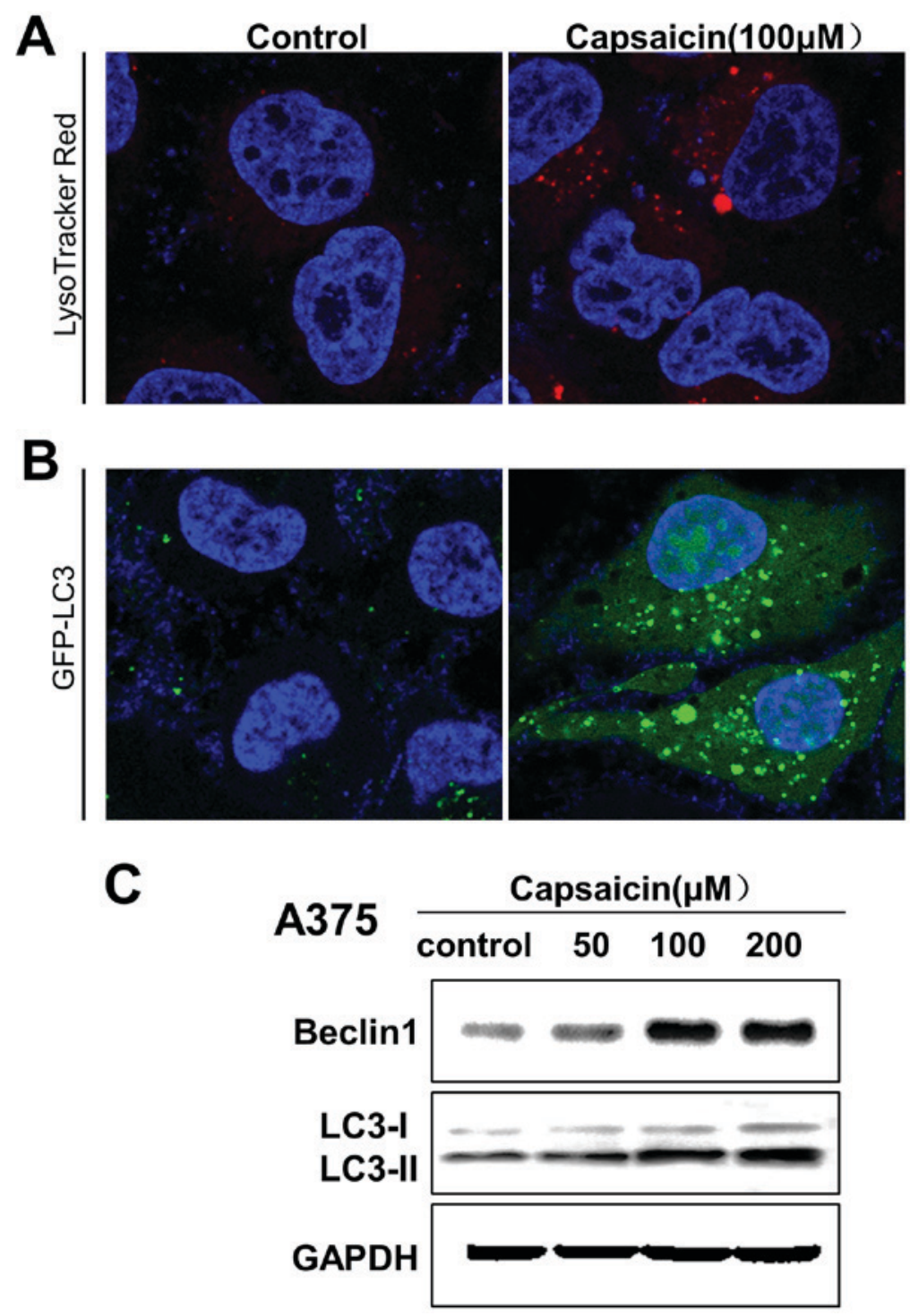

Figure 3. Induction of autophagy by capsaicin in human melanoma cells. (A) Cells were treated with capsaicin (100 $\mu \mathrm{M})$ for $24 \mathrm{~h}$ following incubation with $50 \mathrm{nM}$ LysoTracker ${ }^{\circledast}$ Red DND-99. Lysosomes and autolysosomes were labeled with LysoTracker ${ }^{\circledast}$. The red color intensity reflects cellular acidic compartments. Images were captured by fluorescence. Scale bar=5 $\mu \mathrm{m}$. (B) Melanoma cells were transiently transfected with GFP-LC3 plasmid for $24 \mathrm{~h}$ and treated with or without capsaicin $(100 \mu \mathrm{M})$ for $24 \mathrm{~h}$. The green puncta represent formation of autophagosomes. Immunofluorescence images were captured using a fluorescence microscope. Scale bar $=5 \mu \mathrm{m}$. (C) Cells were treated with various concentrations of capsaicin for $24 \mathrm{~h}$. Western blotting was performed to examine the expression levels of LC3-I, LC3-II and beclin 1.

apoptosis $(13,36)$. Therefore, an intriguing area in the field is the study of natural dietary phytochemicals, including capsaicin, for safe and effective treatment of melanoma.

In the present study, the human melanoma A375 and C8161 cell lines were selected to analyze the chemotherapeutic capacity of capsaicin for human melanoma. The data revealed that capsaicin may suppress cell proliferation, induce apoptosis and induce autophagy via the upregulation of expression levels of cleaved caspase-3, cleaved PARP, beclin 1 and two types of LC3B proteins in human melanoma cells. Additionally, the results of the present study revealed that inhibiting autophagy may strengthen the negative effect of capsaicin on melanoma cell viability, and indicated that capsaicin-induced autophagy may protect cell survival.

Apoptosis and autophagy jointly determine cellular fate (37). PCD that culminates in rapid cell loss is required to maintain homeostasis and is involved in the host response to pathogens. This process can be regulated or unregulated, and apoptosis is known as the regulated type (38). The regulation of apoptosis is divided into two major pathways: The extrinsic (death receptor-mediated) pathway and intrinsic (mitochondria-mediated) pathway, which are triggered by plasma-membrane receptors with soluble molecules or by various mitochondrial stimuli, respectively (39). Caspase-3, one of the 13 aspartate-specific cysteine proteases in the caspase family, serves a central role in the execution of apoptosis, and is primarily responsible for the cleavage of PARP during cell death (40). Previous studies have reported that cell apoptosis is triggered by caspase-dependent or caspase-independent pathways with the former being the most common $(18,36,39,40)$. Cleavage of PARP is considered a central indicator of apoptosis (41). Our results indicated that capsaicin induced apoptosis in human melanoma cells through activation of caspase- 3 and PARP. 
A
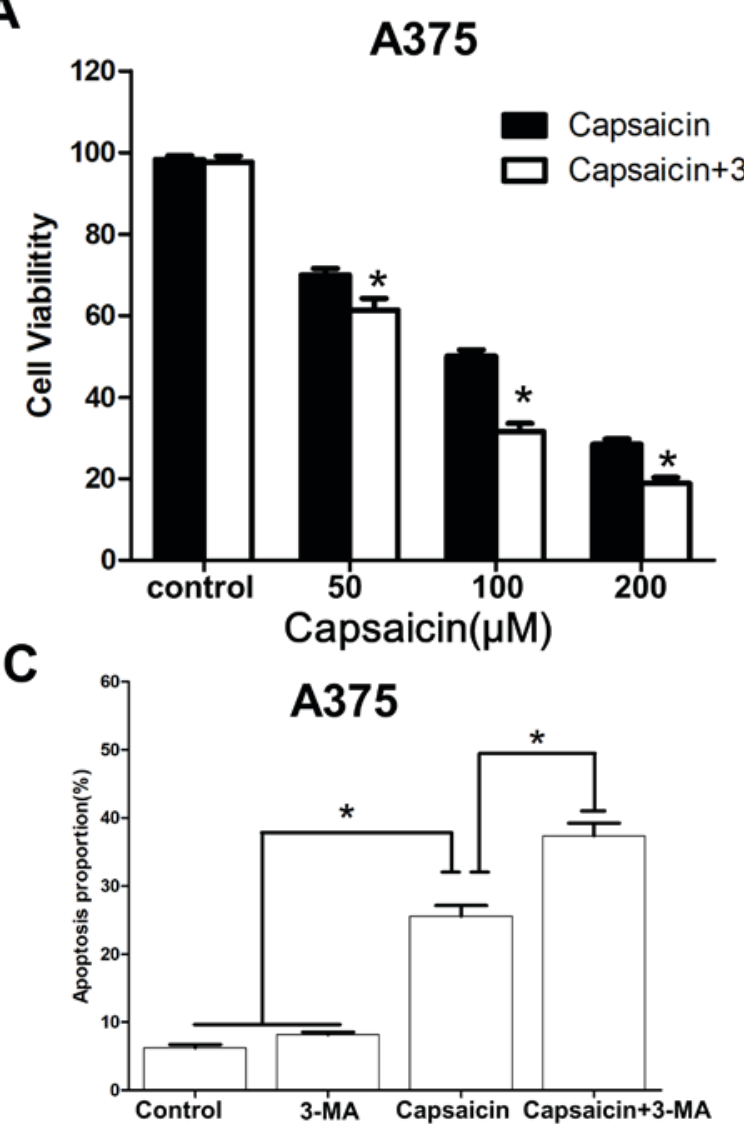

Control

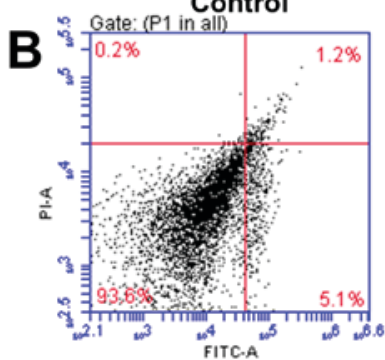

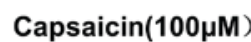

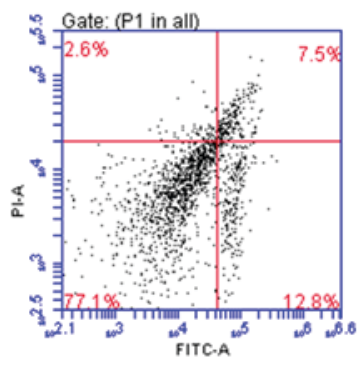

D

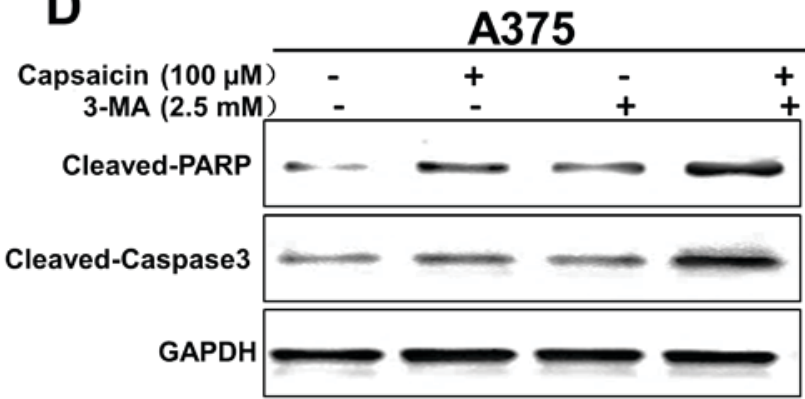

Figure 4. Inhibition of autophagy increases capsaicin-induced apoptosis. (A) A375 cells were incubated with 3-MA (2.5 mM) for 2 h, and subsequently treated with various concentrations of capsaicin for $24 \mathrm{~h}$, followed by a Cell Counting kit-8 assay to determine cell viability. (B) Following treatment with capsaicin $(200 \mu \mathrm{M})$ and 3-MA $(2.5 \mathrm{mM})$ for $24 \mathrm{~h}$, A375 cells were incubated with FITC-conjugated Annexin V/PI and the differences in induction of apoptosis were analyzed by flow cytometry. (C) Histograms indicating the proportions of apoptotic cells from three separate experiments. (D) Western blot analysis of the expression levels of the apoptosis-associated proteins cleaved PARP and caspase-3. $\mathrm{P}<0.05$, compared with capsaicin treatment group or control group.

In this study, following capsaicin treatment, the proportion of LC3B-I, LC3B-II and beclin 1 in human melanoma cells was increased as determined by immunoblotting. The present study demonstrated that capsaicin could induce autophagy, which is the phenomenon of cell 'self-eating' (42). The mechanism of autophagy is typically a stress adaptation in response to various stress stimuli, including starvation, hypoxia, endoplasmic reticulum stress and oxidative stress (43). It has been demonstrated that capsaicin could increase levels of the autophagy markers LC3-II and autophagy related 5, enhancing p62 and Fap-1 degradation, and increasing caspase-3 activity to induce autophagy and apoptosis, respectively $(13,42)$. Previously, the dual roles of autophagy in cancer have been verified, namely, protecting cell survival or contributing to cell death $(44,45)$. Autophagy functions as a recycling process, being principally cytoprotective, recycling long-lived proteins, and defending cells from damaged organelles and protein aggregates. In contrast, excessive autophagy can induce cytotoxicity, which promotes cell death. When flawed apoptosis is induced in normal cells or cancer cells, or apoptosis blocks tumor development, autophagy may act as a backup strategy to stop cell processes or a strategy to promote other cell death mechanisms (46). In the present study, inhibition of autophagy by 3 -MA increased the expression levels of cleaved caspase-3 and cleaved PARP, which may lead to an increase in melanoma cell death. These findings suggested that, in human melanoma cells, capsaicin-induced autophagy may serve a prosurvival role by suppressing apoptosis. Therefore, autophagy cannot only be considered a tumor-inhibiting process but may also be considered a tumor-promoting process. In summary, agents that inhibit autophagy could be used as adjuvants for capsaicin and may be used for antitumor treatment in the future.

In conclusion, capsaicin was demonstrated to exert a negative effect on cancer cell viability, and induced apoptosis of human melanoma A375 and C8161 cells via the activation of cleaved caspase-3 and PARP. Additionally, capsaicin-triggered autophagy contributed to cell survival by suppressing apoptosis of melanoma cells. However, in order for capsaicin to become a drug candidate for melanoma treatment, further issues need to be clarified: The precise dose-effect association between capsaicin and triggered autophagy; whether there could be a 'double-edged sword' effect of capsaicin-triggered autophagy when culturing melanoma cells with more specific concentrations of capsaicin; the mechanism and pathway by which capsaicin activates apoptosis and autophagy; and whether 
capsaicin exerts favorable antitumor effects in vivo. These issues will be investigated in a future study.

\section{Acknowledgements}

Not applicable.

\section{Funding}

This study was supported by the Science Foundation of Shandong Province (grant no. S20160921).

\section{Availability of data and materials}

The datasets used and/or analyzed during the current study are available from the corresponding author on reasonable request.

\section{Authors' contributions}

HC performed the experiments, drafted the manuscript and analyzed the data. ML assisted with the data analysis. XW was responsible for the study design and final approval of the manuscript. All authors read and approved the final version of the manuscript.

\section{Ethics approval and consent to participate}

Not applicable.

\section{Patient consent for publication}

Not applicable.

\section{Competing interests}

The authors declare that they have no competing interests.

\section{References}

1. Schadendorf D, Fisher DE, Garbe C, Gershenwald JE, Grob JJ, Halpern A, Herlyn M, Marchetti MA, McArthur G, Ribas A, et al: Melanoma. Nat Rev Dis Primers 1: 15003, 2015.

2. Leiter U and Garbe C: Epidemiology of melanoma and nonmelanoma skin cancer-the role of sunlight. Adv Exp Med Biol 624: 89-103, 2008.

3. Wei W, Ehlerding EB, Lan X, Luo Q and Cai W: PET and SPECT imaging of melanoma: The state of the art. Eur J Nucl Med Mol Imaging 45: 132-150, 2018.

4. Schadendorf D and Hauschild A: Melanoma in 2013: Melanoma-the run of success continues. Nat Rev Clin Oncol 11: 75-76, 2014.

5. Balch CM, Gershenwald JE, Soong SJ, Thompson JF, Atkins MB, Byrd DR, Buzaid AC, Cochran AJ, Coit DG, Ding S, et al: Final version of 2009 AJCC melanoma staging and classification. J Clin Oncol 27: 6199-6206, 2009.

6. Srinivasan K: Biological activities of red pepper (Capsicum annuum) and its pungent principle capsaicin: A review. Crit Rev Food Sci Nutr 56: 1488-1500, 2016.

7. Ludy MJ, Moore GE and Mattes RD: The effects of capsaicin and capsiate on energy balance: Critical review and meta-analyses of studies in humans. Chem Senses 37: 103-121, 2012.

8. Patel S, Trueman D, Bentley A, Poole C and Chambers C: Cost-effectiveness of capsaicin $8 \%$ patch (Qutenza(tm)) compared with pregabalin for the treatment of patients with peripheral neuropathic pain (Pnp) in Scotland. Value Health 17: A531, 2014
9. Fattori V, Hohmann MS, Rossaneis AC, Pinho-Ribeiro FA and Verri WA: Capsaicin: Current understanding of its mechanisms and therapy of pain and other pre-clinical and clinical uses. Molecules 21: pii: E844, 2016.

10. Bernstein JA, Davis BP, Picard JK, Cooper JP, Zheng S and Levin LS: A randomized, double-blind, parallel trial comparing capsaicin nasal spray with placebo in subjects with a significant component of nonallergic rhinitis. Ann Allergy Asthma Immunol 107: 171-178, 2011.

11. Díaz-Laviada I and Rodríguez-Henche N: The potential antitumor effects of capsaicin. Prog Drug Res 68: 181-208, 2014.

12. Ramos-Torres Á, Bort A, Morell C, Rodríguez-Henche N and Díaz-Laviada I: The pepper's natural ingredient capsaicin induces autophagy blockage in prostate cancer cells. Oncotarget 7: 1569-1583, 2016

13. Lin YT, Wang HC, Hsu YC, Cho CL, Yang MY and Chien CY: Capsaicin induces autophagy and apoptosis in human nasopharyngeal carcinoma cells by downregulating the $\mathrm{PI} 3 \mathrm{~K} / \mathrm{AKT} / \mathrm{mTOR}$ pathway. Int J Mol Sci 18: pii: E1343, 2017.

14. Yang KM, Pyo JO, Kim GY, Yu R, Han IS, Ju SA, Kim WH and Kim BS: Capsaicin induces apoptosis by generating reactive oxygen species and disrupting mitochondrial transmembrane potential in human colon cancer cell lines. Cell Mol Biol Lett 14: 497-510, 2009.

15. Zhang R, Xia Y, Wang Z, Zheng J, Chen Y, Li X, Wang Y and Ming H: Serum long non coding RNA MALAT-1 protected by exosomes is up-regulated and promotes cell proliferation and migration in non-small cell lung cancer. Biochem Biophys Res Commun 490: 406-414, 2017.

16. Huang SP, Chen JC, Wu CC, Chen CT, Tang NY, Ho YT, Lo C, Lin JP, Chung JG and Lin JG: Capsaicin-induced apoptosis in human hepatoma HepG2 cells. Anticancer Res 29: 165-174, 2009.

17. Ouyang L, Shi Z, Zhao S, Wang FT, Zhou TT, Liu B and Bao JK: Programmed cell death pathways in cancer: A review of apoptosis, autophagy and programmed necrosis. Cell Prolif 45: 487-498, 2012.

18. Jun HS, Park T, Lee CK, Kang MK, Park MS, Kang HI, Surh YJ and Kim OH: Capsaicin induced apoptosis of B16-F10 melanoma cells through down-regulation of Bcl-2. Food Chem Toxicol 45: 708-715, 2007.

19. Eisenberg-Lerner A and Kimchi A: The paradox of autophagy and its implication in cancer etiology and therapy. Apoptosis 14: 376-391, 2009.

20. Yang ZJ, Chee CE, Huang S and Sinicrope FA: The role of autophagy in cancer: Therapeutic implications. Mol Cancer Ther 10: 1533-1541, 2011.

21. Maiuri MC, Zalckvar E, Kimchi A and Kroemer G: Self-eating and self-killing: Crosstalk between autophagy and apoptosis. Nat Rev Mol Cell Biol 8: 741-752, 2007.

22. Lo JA and Fisher DE: The melanoma revolution: From UV carcinogenesis to a new era in therapeutics. Science 346: 945-949, 2014.

23. Lin JY and Fisher DE: Melanocyte biology and skin pigmentation. Nature 445: 843-850, 2007.

24. Dong J, Phelps RG, Qiao R, Yao S, Benard O, Ronai Z and Aaronson SA: BRAF oncogenic mutations correlate with progression rather than initiation of human melanoma. Cancer Res 63: 3883-3885, 2003

25. Flaherty KT, Puzanov I, Kim KB, Ribas A, McArthur GA, Sosman JA, O'Dwyer PJ, Lee RJ, Grippo JF, Nolop K and Chapman PB: Inhibition of mutated, activated BRAF in metastatic melanoma. N Engl J Med 363: 809-819, 2010.

26. Hauschild A, Grob JJ, Demidov LV, Jouary T, Gutzmer R, Millward M, Rutkowski P, Blank CU, Miller WH Jr, Kaempgen E, et al: Dabrafenib in BRAF-mutated metastatic melanoma: A multicentre, open-label, phase 3 randomised controlled trial. Lancet 380: 358-365, 2012.

27. Chapman PB, Hauschild A, Robert C, Haanen JB, Ascierto P, Larkin J, Dummer R, Garbe C, Testori A, Maio M, et al: Improved survival with vemurafenib in melanoma with BRAF V600E mutation. N Engl J Med 364: 2507-2516, 2011.

28. Ribas A, Gonzalez R, Pavlick A, Hamid O, Gajewski TF, Daud A, Flaherty L, Logan T, Chmielowski B, Lewis K, et al: Combination of vemurafenib and cobimetinib in patients with advanced BRAF (V600)-mutated melanoma: A phase 1b study. Lancet Oncol 15: 954-965, 2014.

29. Dvořánková B, Szabo P, Kodet O, Strnad H, Koláŕ M, Lacina L, Krejčí E, Naňka O, Šedo A and Smetana K Jr: Intercellular crosstalk in human malignant melanoma. Protoplasma 254: 1143-1150, 2017. 
30. Toh CC, Lee TS and Kiang AK: The pharmacological actions of capsaicin and analogues. Br J Pharmacol Chemother 10: 175-182, 1955.

31. Sekine R, Satoh T, Takaoka A, Saeki K and Yokozeki H: Anti pruritic effects of topical crotamiton, capsaicin, and a corticosteroid on pruritogen-induced scratching behavior. Exp Dermatol 21: 201-204, 2012.

32. Liao HT, Lee HJ, Ho YC and Chiou LC: Capsaicin in the periaqueductal gray induces analgesia via metabotropic glutamate receptor-mediated endocannabinoid retrograde disinhibition. $\mathrm{Br}$ J Pharmacol 163: 330-345, 2011.

33. Clark R and Lee SH: Anticancer properties of capsaicin against human cancer. Anticancer Res 36: 837-843, 2016.

34. Chapa-Oliver AM and Mejía-Teniente L: Capsaicin: From plants to a cancer-suppressing agent. Molecules 21: pii: E931, 2016.

35. Shin DH, Kim OH, Jun HS and Kang MK: Inhibitory effect of capsaicin on B16-F10 melanoma cell migration via the phosphatidylinositol 3-kinase/Akt/Racl signal pathway. Exp Mol Med 40: 486-494, 2008.

36. Lin CH, Lu WC, Wang CW, Chan YC and Chen MK: Capsaicin induces cell cycle arrest and apoptosis in human $\mathrm{KB}$ cancer cells. BMC Complement Altern Med 13: 46, 2013.

37. Liu Z, Ouyang L, Peng H and Zhang WZ: Oridonin: Targeting programmed cell death pathways as an anti-tumour agent. Cell Prolif 45: 499-507, 2012.

38. Hail N Jr, Carter BZ, Konopleva M and Andreeff M: Apoptosis effector mechanisms: A requiem performed in different keys. Apoptosis 11: 889-904, 2006.

39. Mukhopadhyay S, Panda PK, Sinha N, Das DN and Bhutia SK Autophagy and apoptosis: Where do they meet? Apoptosis 19 $555-566,2014$.
40. Boulares AH, Yakovlev AG, Ivanova V, Stoica BA, Wang G, Iyer S and Smulson M: Role of poly(ADP-ribose) polymerase (PARP) cleavage in apoptosis. Caspase 3-resistant PARP mutant increases rates of apoptosis in transfected cells. J Biol Chem 274: 22932-22940, 1999.

41. Kulms D and Schwarz T: Molecular mechanisms of UV-induced apoptosis. Photodermatol Photoimmunol Photomed 16: 195-201, 2000.

42. Liu YP, Dong FX, Chai X, Zhu S, Zhang BL and Gao DS: Role of autophagy in capsaicin-induced apoptosis in U251 glioma cells. Cell Mol Neurobiol 36: 737-743, 2016.

43. Radogna F, Dicato M and Diederich M: Cancer-type-specific crosstalk between autophagy, necroptosis and apoptosis as a pharmacological target. Biochem Pharmacol 94: 1-11, 2015.

44. Li M, Tan J, Miao Y, Lei P and Zhang Q: The dual role of autophagy under hypoxia-involvement of interaction between autophagy and apoptosis. Apoptosis 20: 769-777, 2015.

45. Fu D, Yu JY, Yang S, Wu M, Hammad SM, Connell AR, Du M, Chen J and Lyons TJ: Survival or death: A dual role for autophagy in stress-induced pericyte loss in diabetic retinopathy. Diabetologia 59: 2251-2261, 2016.

46. Ravegnini G, Sammarini G, Nannini M, Pantaleo MA, Biasco G, Hrelia P and Angelini S: Gastrointestinal stromal tumors (GIST): Facing cell death between autophagy and apoptosis. Autophagy 13: 452-463, 2017.

(i) (2) This work is licensed under a Creative Commons Attribution-NonCommercial-NoDerivatives 4.0 International (CC BY-NC-ND 4.0) License. 